\title{
HEAVY EPISODIC DRINKING AND ALCOHOL-RELATED INJURIES: AN OPEN COHORT STUDY AMONG COLLEGE STUDENTS.
}

\author{
Authors: Francisco Caamaño-Isorna, Lucía Moure-Rodríguez, Sonia Doallo , \\ Montserrat Corral, Socorro Rodriguez Holguín, Fernando Cadaveira
}

This is the peer reviewed version of the following article: Caamaño-Isorna F; Moure-Rodríguez L; Doallo S; Corral M;, Rodriguez Holguín S; Cadaveira F (2017). Heavy episodic drinking and alcohol-related injuries: an open cohort study among college students. Accident Analysis \& Prevention, 100, 23-29. doi: 10.1016/j.aap.2016.12.012 0001-4575. This article may be used for non-commercial purposes in accordance with Elsevier Terms and Conditions for Use of SelfArchived Versions 
1 Heavy episodic drinking and alcohol-related injuries: An open cohort study 2 among college students.

3

4 Authors: Francisco Caamaño-Isorna ${ }^{\mathrm{a}}$, Lucía Moure-Rodríguez ${ }^{\mathrm{a}}$, Sonia Doallo ${ }^{\mathrm{b}}$, Montserrat 5 Corral $^{\mathrm{b}}$, Socorro Rodriguez Holguín ${ }^{\mathrm{b}}$, Fernando Cadaveira ${ }^{\mathrm{b}}$.

6 15784 Santiago de Compostela. Spain

16 lucia.moure@rai.usc.es 
Heavy Episodic Drinking \& Alcohol-Related Injuries

21

22

23

24

\section{Abstract}

Aim: The objective of this study is to assess the effects of Heavy Episodic Drinking (HED) on the incidence of alcohol-related injuries among university students in Spain, taking sex into consideration.

Methods: We carried out an open cohort study among college students in Spain (992 women and 371 men). HED and alcohol-related injuries were measured by question 3th and 9th of Alcohol Use Disorders Identification Test to every participant at the ages of 18, 20, 22, 24 and 27. For data analysis we used a Multilevel Logistic Regression for repeated measures adjusting for alcohol and cannabis use.

Results: The incidence rate of alcohol-related injuries was 0.028 year $^{-1}$ for females and 0.036 year $^{-1}$ for males. The multivariate analysis showed that among females a high frequency of HED and use of cannabis are risk factors for alcohol-related injuries (Odds Ratio [OR]=2.64 and $\mathrm{OR}=3.68)$, while being more than 23 is a protective factor $(\mathrm{OR}=0.34)$. For males, bivariate analysis also showed HED like risk factor $(\mathrm{OR}=4.69$ and $\mathrm{OR}=2.51)$. Finally, the population attributable fraction for HED among females was $37.12 \%$.

Conclusions: HED leads to an increase of alcohol-related injuries in both sexes and being over 23 years old acts as a protective factor among women. Our results suggest that about one third of alcohol-related injuries among women could be avoided by removing HED.

Key words: youth, alcohol, cohort study, injury, heavy episodic drinking. 
Heavy Episodic Drinking \& Alcohol-Related Injuries

\section{Introduction}

Risk behavior, including substance use, is common among youth.[Pickett et al., 2002] Specifically, rates of heavy episodic drinking (HED) behavior are increasing among young people around the world.[Jernigan, 2001] This alcohol consumption pattern is characterized by the intake of large amounts of alcohol in a short period of time, reaching blood alcohol concentrations of $0.8 \mathrm{~g} / \mathrm{l}$ or greater.[National Institute on Alcohol Abuse and Alcoholism, 2016] Reich's research found that about 58\% of youth between 22 and 23 years old practice HED. This proportion decreased after 5 years, among the same participants, to $42 \%$. [Reich et al., 2015] Spain is no exception, with high rates of HED. The prevalence of HED in Spain among youth from 14 to 18 years old is $41.8 \%$.[Delegación del Gobierno para el Plan Nacional sobre Drogas, 2013]

During the college years people acquire behavior patterns and life styles that they maintain through adulthood.[Schulenberg et al., 1996] Excessive alcohol consumption during youth is also associated with an increased risk of dependence and alcohol-related problems in adulthood.[Grant et al., 2006] Importantly, cerebral maturity, specifically in frontal and temporal regions, continue to develop during adolescence and youth. These regions are also particularly susceptible to the effects of alcohol.[Guerri and Pascual, 2010] Other consequences that have been associated with HED are lower academic achievement,[Mota et al., 2010; Powell et al., 2004] unsafe sex [Cooper, 2002; Moure-Rodríguez et al.,2016] and car accidents.[Valencia-Martín JL et al., 2008; Wechsler et al., 2003]

Previous studies have also shown a higher risk of alcohol-related injuries among individuals that present with HED, compared to those who do not show this pattern of consumption. [Rehm et al., 2002; Watt et al., 2003]. Mundt, et al. found a 43\% occurrence of alcohol-related injuries among Heavy Episodic Drinkers compared with 10\% among non-HED, and McLeod has found three times the risk of these injuries among subjects who practice HED.[Mcleod et 
Heavy Episodic Drinking \& Alcohol-Related Injuries

65

66

67

68

69

70

71

72

73

74

75

76

al., 1999; Mundt et al., 2009]. Finally, previous studies have also shown the prevalence of HED is different among both female and male college students,[Moure-Rodríguez et al., 2016;

Wicki et al., 2010] and HED is also significantly different from the ages of 18 to 27 years old.[Moure-Rodríguez et al., 2016] Not to mention, HED's consequences could be different as well.[Caamano-Isorna et al., 2017; Kypri et al., 2009; Wiersma et al., 2002].

0 Furthermore, it has been observed the consequences of alcohol use vary considerably in 1 different countries.[Graham et al., 2011] Despite our previous results of this cohort,[Moure2 Rodríguez et al., 2014] we are not aware of any similar longitudinal studies in European 3 countries with traditional alcohol use.

74 The objective of this study is to assess the effects of HED on the incidence of alcohol-related 7 injuries among university students in Spain, taking sex into consideration. 
Heavy Episodic Drinking \& Alcohol-Related Injuries

\section{Methods}

\subsection{Design, population and sample}

An open cohort analysis was conducted within the framework of a cohort study designed to assess neurocognitive and social consequences of alcohol use. The study was carried out between November 2005 and February 2015 college students from a large public university at the north west of Spain. We performed a cluster sampling. From each one of the 33 university schools, at least one of the freshman year classes was randomly selected (a total of 53 classes). The number of classes selected on each university school was proportional to its number of students. All students present in the class on the day of the survey were invited to participate in the study $(\mathrm{n}=1,382)$. Abstinent subjects and subjects who were not born in 1987 were excluded from the study. The study follows the principles of the Declaration of Helsinki and was approved by the university ethics committee (October 2004).

\subsection{Data collection procedures}

Participants were evaluated via a self-administered questionnaire in the classroom in November 2005 and again in November 2007. Students that provided their phone number were further evaluated by phone at 4.5- 6.5-, and 9.0- year follow-up. On all five occasions, alcohol consumption and alcohol-related injuries were measured using the Galician validated version of the Alcohol Use Disorder Identification Test (AUDIT).[Saunders et al., 1993; Varela et al., 2005] At baseline and at the 2-year follow-up, participants responded to additional questions about age of onset of alcohol consumption and about cannabis consumption.

\subsection{Definition of variables}

In order to characterize the samples, several variables were considered: sex, place of residence (parental home/away from the parental home), university entrance grade ( 5 - <7 points; $7-<9$ points; and 9 - 10 points); and maternal educational level (primary school/high 
Heavy Episodic Drinking \& Alcohol-Related Injuries

101 school/university). The subjects were also asked about the age of onset of use of alcohol using

102 the following question: "At what age did you start drinking alcohol?" Four categories were

103 defined for age of onset of use (after 16 years old, at 16, at 15, before the age of 15).

104 Independent variables

105 Heavy episodic drinking (HED) at 18, 20, 22, and 24 years old. Question 3 of the AUDIT:

106 "How often do you have 6 or more alcoholic drinks on a single occasion? Never; less than once

107 a month; at least once a month; at least once a week; daily or almost daily". The categories at

108 least once a month; at least once a week; and daily or almost daily were recategorized to More

109 frequently. In Spain, a standard drink corresponds to 10 grams of alcohol, therefore the

110 consumption of 6 alcoholic beverages in 2 hours results in blood alcohol concentration levels

111 of $0.8 \mathrm{~g} / \mathrm{l}$.

112 Frequency of alcohol consumption at 18, 20, 22 and 24 years old. Question 1 of the AUDIT:

113 "How often do you have a drink containing alcohol? Never; monthly or less; two to four times

114 a month; two to three times a week; four or more times a week".

115 Number of alcoholic drinks on a typical day at 18, 20, 22 and 24 years old. Question 2 of the

116 AUDIT: "How many alcoholic drinks do you have on a typical day when you are drinking? 1

117 or $2 ; 3$ or $4 ; 5$ or $6 ; 7$ to $9 ; 10$ or more".

118 Cannabis consumption at 18, and 20 years old. This variable was measured with the question

119 "Do you consume cannabis when you go out? Never; sometimes; most of the times; always".

120 The categories "most of the times" and "always" were recategorized to Usually.

121 Dependent variable

122 Alcohol-related injuries at 20, 22, 24 and 27 years old. Question 9 of the AUDIT: "Have you

123 or someone else been injured as a result of your drinking? No; yes, but not during the last year;

124 yes, during the last year". 
Heavy Episodic Drinking \& Alcohol-Related Injuries

2.4 Statistical analysis

127

The follow-up was structured in 4 periods: 11/2005- 11/2007 (2 years); 11/2007 - 05/2010

(2.5 years); 05/2010 - 05/2012 (2 years); and 05/2012 - 02/2015 (2.5 years). Because of the

open cohort design of the study, the conditions of subjects may have changed during followup. While the 9th AUDIT question refers to alcohol related injuries suffered in the past, the independent variables about alcohol consumption and cannabis consumption were referred about the present. Therefore, the variable "alcohol-related injuries" measured in 11/2007, 05/2010, 05/2012 and 02/2015 was considered as the effect of both the number of alcoholic drinks on a typical day (Question 2 of the AUDIT) and the HED (Question 3 of the AUDIT) having occurred in 11/2005, 11/2007, 05/2010, and 05/2012 respectively. Since we have only two measures of cannabis use (11/2005 and 11/2007), we considered the alcohol-related injuries in 11/2007 as the effect of the cannabis use in 11/2005, and alcohol related injuries for the rest of the periods as the effect of cannabis use at 11/2007. At each stage of the study the subjects than answered "Never" to the first question of the AUDIT were excluded.

We used multilevel logistic regression for repeated measures to obtain adjusted Odds Ratios

141 for Alcohol-related injuries. Cannabis consumption and number of alcoholic drinks on a typical

142 day (Question 2 of the AUDIT) were also considered as independent variables, because it is 143 known that both variables can result in a lower risk perception and decreased attention, which 144 may consequently lead to injury. Adjusting by both variables, we can therefore identify the 145 specific effect associated to HED. Frequency of alcohol consumption (Question 1 of the 146 AUDIT) was also considered in order to remove the abstinent subjects. The university school 147 and the class were considered as randomized variables. The follow-up time was included as an 148 offset term. Data were analyzed using Generalized Linear Mixed Models from the SPSS 20.0. 
Heavy Episodic Drinking \& Alcohol-Related Injuries

149 Finally, in order to calculate the population impact measures, we considered the following

150 formulas.[Llorca et al., 2001] (1) To calculate the proportion of alcohol related injuries in

151 exposed subjects attributable to HED 1-(1/OR); and (2) To calculate the population attributable

152 fraction $p c-(p c / O R)$, being pc the prevalence of exposition in ill subjects. For both formulas,

153 OR was calculated dichotomizing the HED variable (yes/no).

154 
Heavy Episodic Drinking \& Alcohol-Related Injuries

156 The response rate at the beginning of the study was $99.6 \%$. Characteristics of female and male

157 initial and follow-up samples are shown in tables 1 and 2.

158

159 Table 1. Characteristics of females in the initial and follow-up samples. Santiago de Compostela, Spain. 2005-

160

2015.

\section{Percentage or mean $(95 \% \mathrm{CI})$}

Initial 2-year follow-up 4-year follow-up 6-year follow-up 9-year follow-up

(18-19 years old) (20-21 years old) (22-23 years old) (24-25 years old) (27-28 years old) p-value $\mathrm{n}=992$ $\mathrm{n}=669$ $\mathrm{n}=461$ $\mathrm{n}=266$ $\mathrm{n}=325$

\section{Maternal educational level}

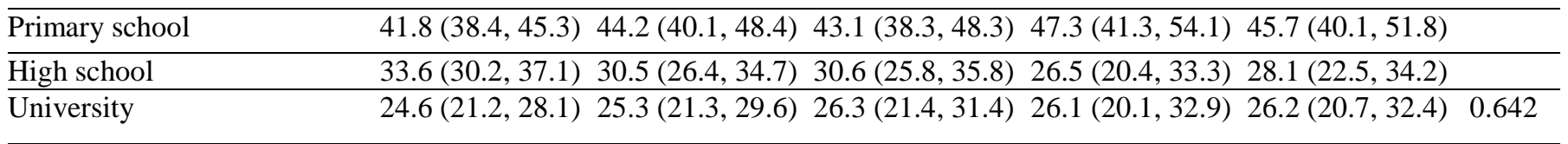

\section{Residence}

\begin{tabular}{llllll}
\hline In parental home & $24.7(22.1,27.5)$ & $22.9(19.7,26.1)$ & $22.2(18.5,26.0)$ & $22.1(18.1,26.1)$ & $20.9(16.5,25.1)$
\end{tabular}

Away from the parental home $75.3(72.6,78.0) 77.1(74.0,80.3) 77.8(74.1,81.6) 77.9(73.9,81.9) \quad 79.1(74.9,83.5) \quad 0.720$

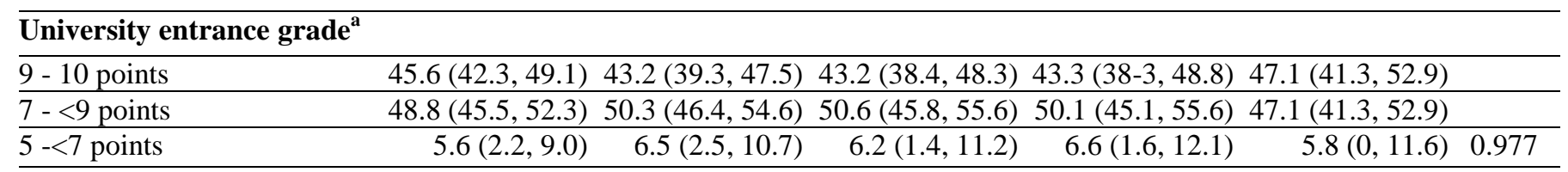

\section{Age of onset of use of \\ alcohol}

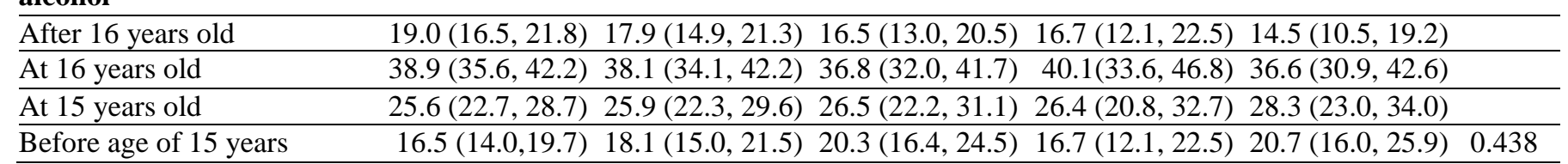

161 a Variable with a scale of 1 to 10

162

163

164 
Heavy Episodic Drinking \& Alcohol-Related Injuries

165 Table 2. Characteristics of males in the initial and follow-up samples. Santiago de Compostela, Spain. 2005-

166

2015.

Percentage or mean (95\% confidence interval)

Initial 2-year follow-up 4-year follow-up 6-year follow-up 9-year follow-up

(18-19 years old) (20-21 years old) (22-23 years old) (24-25 years old) (27-28 years old) p-

$\mathrm{n}=371 \mathrm{n}=206 \quad \mathrm{n}=139 \quad \mathrm{n}=90 \quad$ value

\section{Maternal educational \\ level}

Primary school $\quad 32.0(26.5,37.8) \quad 35.8(28.4,43.3) \quad 41.6(32.8,50.8) 43.0(31.6,54.8) \quad 41.6(31.5,53.5)$

\begin{tabular}{llllll}
\hline High school & $27.6(22.1,33.3)$ & $27.4(19.9,34.9)$ & $25.5(16.8,34.7)$ & $24.1(12.7,35.8)$ & $27.0(16.8,38.9)$
\end{tabular}

\begin{tabular}{lllllll}
\hline University & $40.3(34.8,46.0)$ & $36.8(29.3,44.3)$ & $32.8(24.1,42.0)$ & $32.9(21.5,44.7)$ & $31.5(21.3,43.4)$ & 0.449
\end{tabular}

Residence

\begin{tabular}{llllll}
\hline In parental home & $29.7(25.1,34.5)$ & $27.8(21.9,34.1)$ & $28.8(21.6,36.4)$ & $31.6(23.9,40.6)$ & $28.9(20.0,38.3)$
\end{tabular}

Away from the parental $70.3(65.7,75.1) 72.2(66.3,78.5) \quad 71.2(64.0,78.9) 68.4(60.7,77.4) 71.7(62.2,80.5) \quad 0.949$ home

University entrance

grade $^{\mathbf{a}}$

\begin{tabular}{llllll}
\hline $9-10$ points & $50.7(45.3,56.2)$ & $47.5(40.6,55.0)$ & $50.0(42.0,59.2)$ & $50.0(41.4,60.1)$ & $51.7(41.6,62.7)$
\end{tabular}

\begin{tabular}{llllll}
\hline $7-<9$ points & $42.7(37.3,48.2)$ & $43.6(36.6,51.0)$ & $43.5(35.5,52.7)$ & $42.2(33.6,52.3)$ & $42.7(32.6,53.7)$
\end{tabular}

\begin{tabular}{lllllll}
\hline $5-<7$ points & $6.6(1.1,12.1)$ & $8.9(2.0,16.4)$ & $6.5(0,15.7)$ & $7.8(0,17.8)$ & $5.6(0,16.6)$ & 0.996
\end{tabular}

Age of onset of use of

alcohol

\begin{tabular}{llllll}
\hline After 16 years old & $18.1(12.5,24.1)$ & $16.8(9.2,24.7)$ & $15.5(6.9,25.5)$ & $16.4(6.0,29.7)$ & $18.2(7.8,30.3)$
\end{tabular}

\begin{tabular}{lllllll}
\hline At 16 years old & $36.9(31.2,42.8)$ & $41.0(33.5,49.0)$ & $44.0(35.3,54.0)$ & $50.7(40.3,64.0)$ & $48.1(37.7,60.1)$
\end{tabular}

\begin{tabular}{llllll}
\hline At 15 years old & $21.6(15.9,27.5)$ & $20.2(12.7,28.2)$ & $21.6(12.9,1.6)$ & $23.9(13.4,37.2)$ & $20.8(10.4,32.8)$
\end{tabular}

\begin{tabular}{lllllll}
\hline Before age of 15 years & $23.4(17.8,29.4)$ & $22.0(14.4,30.0)$ & $19.0(10.3,9.0)$ & $9.0(0.0,22.3)$ & $13.0(2.6,25.1)$ & 0.381
\end{tabular}

167 a Variable with a scale of 1 to 10

168

169 The mean follow-up period was 5.3 years and the median follow-up period 4.6 years. The

170 number of alcoholic drinks on a typical day is greater for male students, except in the last

171 period. This number also decreased significantly over the study period for both sexes.

172 Regarding the HED practice, we can see that women have the highest prevalence at 18 while

173 men reach their peak at age 22 (Table 3).

174

175

176

177 
Table 3. Main Characteristics of the College Students throughout the follow-up study. Santiago de Compostela, Spain. $2005-2015$.

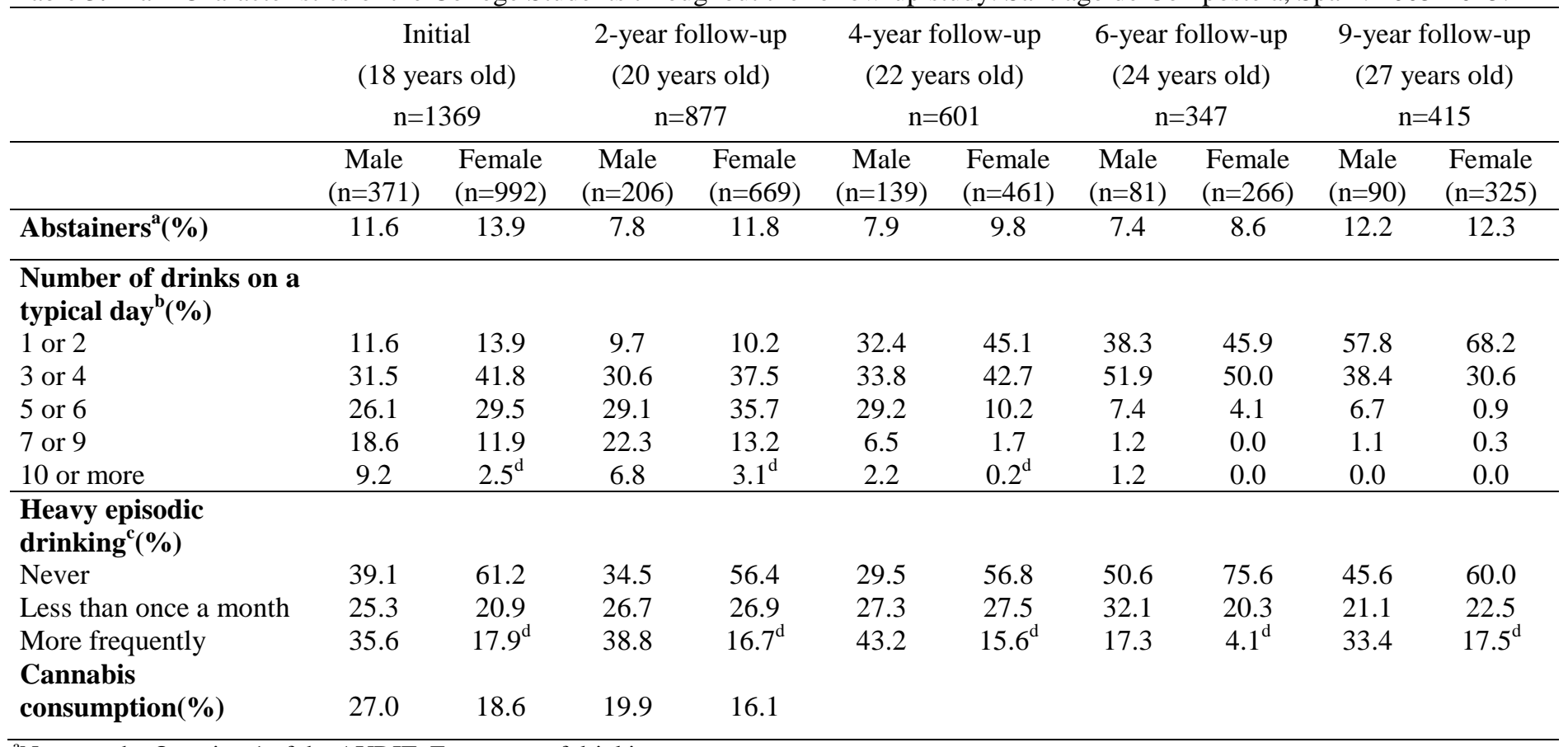

\footnotetext{
${ }^{a}$ Never at the Question 1 of the AUDIT: Frequency of drinking.

${ }^{\mathrm{b}}$ Question 2 of the AUDIT: Typical quantity.

${ }^{c}$ Question 3 of the AUDIT: Frequency of heavy episodic drinking.

${ }^{\mathrm{d}}$ Chi-square $\mathrm{p}<0.05$.
}

179 Among females, 91 cases of alcohol-related injuries were detected in a follow-up period of

$1803,257.00$ years. The incidence rate of alcohol-related injuries during the follow-up was 0.028

181 year ${ }^{-1}$ [95\%CI: 0.022, 0.034]. After adjusting for number of alcoholic drinks on a typical day,

182 multivariate model revealed that a high frequency of HED and cannabis consumption were risk

183 factors for alcohol-related injuries ( $\mathrm{OR}=2.64$ and $\mathrm{OR}=3.68$, respectively), while being more

184 than 23 is a protective factor $(\mathrm{OR}=0.34)$. The number of alcoholic drinks on a typical day was

185 not a significant variable, but it stayed as a part of the definitive model because it was a

186 confounding variable (Table 4).

187 
Table 4. Factors associated with the incidence of alcohol-related injuries during the nine year follow-up period among female participants. Santiago de Compostela, Spain. 2005-2015.

\begin{tabular}{|c|c|c|c|c|c|c|}
\hline & \multicolumn{4}{|c|}{ Bivariate Analysis } & \multicolumn{2}{|c|}{ Multivariate Analysis $^{\mathrm{a}}$} \\
\hline & Cases & $\begin{array}{c}\text { Follow-up } \\
\text { Years }\end{array}$ & $\begin{array}{l}\text { Odds } \\
\text { ratio }\end{array}$ & $\begin{array}{c}95 \% \text { confidence } \\
\text { interval }\end{array}$ & $\begin{array}{l}\text { Odds } \\
\text { ratio }\end{array}$ & $\begin{array}{c}95 \% \text { confidence } \\
\text { interval }\end{array}$ \\
\hline \multicolumn{7}{|c|}{ Age of onset of alcohol use } \\
\hline After 16 years old & 7 & 476.3 & 1 & & 1 & \\
\hline At 16 & 38 & $1,193.2$ & 2.21 & $0.88,5.56$ & 2.16 & $0.93,5.00$ \\
\hline At 15 & 25 & 833.8 & 2.16 & $0.82,5.65$ & 1.74 & $0.72,4.23$ \\
\hline Before 15 years old & 19 & 570.8 & 2.35 & $0.86,6.44$ & 1.64 & $0.65,4.14$ \\
\hline \multicolumn{7}{|l|}{ Heavy episodic drinking ${ }^{b}$} \\
\hline Never & 28 & $1,848.9$ & 1 & & 1 & \\
\hline Less than once a month & 32 & 925.7 & 2.42 & $1.44,4.09$ & 1.64 & $0.94,2.86$ \\
\hline More frequently & 31 & 539.1 & 4.43 & $2.60,7.57$ & 2.64 & $1.46,4.77$ \\
\hline \multicolumn{7}{|l|}{ Cannabis consumption } \\
\hline Never & 58 & $2,669.5$ & 1 & & 1 & \\
\hline Sometimes & 23 & 532.1 & 2.20 & $1.31,3.68$ & 1.49 & $0.85,2.59$ \\
\hline Usually & 10 & 112.1 & 5.51 & $2.56,11.87$ & 3.68 & $1.61,8.38$ \\
\hline \multicolumn{7}{|l|}{ Subjects' age } \\
\hline $18-20$ years & 28 & $1,158.0$ & 1 & & 1 & \\
\hline $20-22$ years & 39 & $1,015.0$ & 1.32 & $0.78,2.23$ & 1.41 & $0.83,2.38$ \\
\hline $22-24$ years & 19 & 625.0 & 1.25 & $0.67,2.34$ & 1.45 & $0.78,2.69$ \\
\hline 24- 27 years & 5 & 432.0 & 0.29 & $0.11,0.80$ & 0.34 & $0.11,0.99$ \\
\hline All subjects & 91 & $3,257.00$ & & & & \\
\hline
\end{tabular}

adjusted for all the variables included in the column and for the question 2 of the AUDIT: "How many alcoholic drinks do you have on a typical day when you are drinking?"

${ }^{\mathrm{b}}$ Question 3 of the AUDIT: "How often do you have six or more drinks on one occasion?"

191 incidence rate was 0.036 year $^{-1}$ [95\%CI: 0.025, 0.049]. Bivariate model revealed that a high

192 frequency of HED and cannabis consumption were risk factors for alcohol-related injuries

$193(\mathrm{OR}=4.69$ and $\mathrm{OR}=2.51$, respectively). No changes are observed with the age (Table 5). Figure

1941 shows the trend of incidence rate of alcohol-related injuries for males and females. 
Heavy Episodic Drinking \& Alcohol-Related Injuries

Table 5. Factors associated with the incidence of alcohol-related injuries during the 9-year follow-up period among male participants. Santiago de Compostela, Spain. 2005-2015.

\begin{tabular}{|c|c|c|c|c|}
\hline & \multirow[b]{2}{*}{ Cases } & & \multicolumn{2}{|c|}{ Bivariate Analysis } \\
\hline & & $\begin{array}{l}\text { Follow-up } \\
\text { Years }\end{array}$ & $\begin{array}{l}\text { Odds } \\
\text { Ratio }\end{array}$ & $\begin{array}{c}95 \% \text { confidence } \\
\text { interval }\end{array}$ \\
\hline \multicolumn{5}{|c|}{ Age of onset of alcohol use } \\
\hline After 16 years old & 2 & 155.5 & 1 & \\
\hline At 16 & 14 & 413.1 & 2.92 & $0.64,13.35$ \\
\hline At 15 & 7 & 198.2 & 2.91 & $0.58,14.57$ \\
\hline Before 15 years old & 11 & 157.1 & 6.8 & $1.42,32.50$ \\
\hline \multicolumn{5}{|c|}{ Heavy episodic drinking ${ }^{a}$} \\
\hline Never & 6 & 347.5 & 1 & \\
\hline Less than once a month & 5 & 275.7 & 1.13 & $0.33,3.84$ \\
\hline More frequently & 25 & 391.0 & 4.69 & $1.83,12.0$ \\
\hline \multicolumn{5}{|l|}{ Cannabis consumption } \\
\hline Never & 25 & 783.6 & 1 & \\
\hline Sometimes & 7 & 170.4 & 1.45 & $0.58,3.62$ \\
\hline Usually & 4 & 60.2 & 2.51 & $0.77,8.19$ \\
\hline \multicolumn{5}{|l|}{ Subjects' age } \\
\hline 18 - 20 years & 11 & 364.0 & 1 & \\
\hline $20-22$ years & 12 & 322.5 & 0.94 & $0.40,2.22$ \\
\hline $22-24$ years & 8 & 190.0 & 1.40 & $0.54,3.62$ \\
\hline $24-27$ years & 5 & 135.0 & 0.86 & $0.28,2.61$ \\
\hline All subjects & 36 & $1,011.5$ & & \\
\hline
\end{tabular}

aQQuestion 3 of the AUDIT: "How often do you have six or more drinks on one occasion?"

201 Fig 1. Incidence rate of alcohol-related injuries at the different ages for males and females.

203 Finally, in relation to population impact measures, our study found that the population

204 attributable fraction for HED among females was 37.12\%. This proportion was not calculated

205 for males given that multivariate analysis cannot be generated. 
Heavy Episodic Drinking \& Alcohol-Related Injuries

\section{Discussion}

208 Our results show a strong association between HED and the incidence of alcohol-related 209 injuries in men and women in the bivariate analysis. This association has only been confirmed 210 for women with multivariate analysis. The relationship persisted after adjusting for 211 confounding variables such as the number of alcoholic drinks consumed on a typical day, and 212 cannabis consumption.

213 Regarding the evolution of the practice of HED we found a bell-shaped trend, which coincides 214 with the trends observed in other countries.[Bewick et al., 2008; Kandeld and Logan, 1984] 215 The fact that women reach their peak HED consumption earlier than men has been observed in 216 other studies and a possible explanation could be an earlier maturity in women.[Andersson et 217 al., 2007; Bates and Labouvie, 1997] Further studies are needed to confirm these results, as 218 these differences in consumption prevalence with respect to sex may have important 219 implications in establishing effective preventative measures.

220 Several papers have previously found an association between alcohol use and injury.[Rehm et 221 al., 2002] Of particular interest is the association of alcohol-related injuries to the volume of 222 alcohol consumed before injury, which seems to be more important than the quantity of alcohol 223 usually consumed or how often alcohol is consumed.[Mcleod et al., 1999] However, most of 224 studies on this topic have been conducted at the emergency departments of hospitals or health 225 centers; thus, they take into account only injuries that require subsequent medical attention. 226 Our study considered all injuries reported by the participants, not only those that need medical 227 attention. Our study therefore analyzed participants' relationships to the characteristic 228 consumption pattern of this vital stage.

229 As mentioned previously, alcohol consumption is influenced by gender. In Mediterranean 230 countries, alcohol use it is traditionally practiced by male, but among young people gendered 
231 differences are decreasing.[Cortés et al., 2011] We have taken gender into account in our 232 analysis to assess whether these differences are maintained among college students. Our study 233 found a significant association between alcohol-related injuries and HED in men, although the 234 sample size did not permit multivariate analysis. Other studies have showed more negative 235 consequences to alcohol use in men.[Graham et al., 2011]

236 Regarding age, we can see that age greater than 23 years old acts as a protective factor for 237 alcohol-related injuries. High doses of alcohol decrease the activity of some brain regions 238 involved in error processing, prevention of compulsive actions, behavior regulation, cognition, 239 and coordination of motor activities.[Anderson et al., 2011] This could increase the risk of 240 injury. The fact that risk of injury is lower after 23 years of age can be explained by tolerance 241 developed by students, over time. Another possible reason could be that individuals at this age 242 are more mature, so they practice Binge Drinking in safer contexts and assume fewer risks, and 243 therefore injuries are less frequent.[O`Malley, 2004]

244 The fact that cannabis use was found to be risk factor for alcohol-related injuries allows us to 245 suggest that multiple drug use may be an interesting point of evaluation in future studies 246 among this population.

247 Our findings suggest that an important part of alcohol-related injuries among college students, 248 all through university period and also when this period is over, is due to HED consumption 249 pattern. Preventive measures, therefore, must be implemented in order to reduce heavy 250 episodic drinking practices among college students and so as to avoid an important part of the 251 negative consequences of alcohol consumption, such as alcohol-related injuries. It is 252 fundamental to act to reduce the accessibility of alcohol to college students through strictly 253 applied legislative measures. 
254 Young people are particularly affected by alcohol prices because of their limited economic 255 resources. Therefore, administrative measures, such as raising taxes on alcoholic beverages, 256 would act to reduce their alcohol consumption.[Ivano Scandurra et al., 2011; Laixuthai and 257 Chaloupka, 1993] It would also be effective to ban promotional packaging that mixes alcohol 258 with sodas, thus promoting excessive alcohol consumption in youth. Increasing the minimum 259 legal age for alcohol consumption has been associated with fewer car accidents and suicide 260 among young people, even without tight compliance control.[Griffith, 1997]

261 Youth are especially vulnerable to alcohol promotion and publicity; binge drinkers in 262 particular seem to be the most susceptible.[Sassi, 2015] Strict policy for regulating and 263 limiting the advertisement of these products, therefore, is essential.

264 Other measures, such as brief motivational interventions or skill-based interventions, appear 265 effective among young people, specifically among college students when they are given 266 personalized feed-back.[Larimer and Cronce, 2007] College freshmen are particularly 267 disposed to these interventions and therefore a general intervention could be interesting in this 268 subpopulation.[Larimer and Cronce, 2007]

269 We must take into account that our social context may generate strong opposition to any 270 measures that try to decrease alcohol consumption. On one hand, Spanish society is quite 271 permissive with regards to alcohol use. However, Spain alcohol industry is also very 272 important -- Spain being one of the most important wine producers in the world with an 273 important tourism industry.[Calafat, 2002]

274 Our study largely confirms what is known from the literature: HED is related to alcohol275 related injuries. We do not know of, apart from our previous studies, another longitudinal 276 study in Mediterranean European Countries, which associates the HED with alcohol-related 277 injuries among college students. We must not forget that this cohort has been followed up 
beyond the university period and the association does not disappear. This is an interesting result as tends to be understood in Mediterranean countries as a pattern of consumption limited to the vital period of adolescence and early youth. Our university students did not only continue practicing HED after ending their university periods, they also continued suffering some of its negative consequences. Our results highlight the importance of avoiding HED among youth.

There are six main limitations to this study: 1) there is a possibility of selection bias, due to loss of subjects at follow-up. However, the absence of significant differences between the initial samples and the follow-up samples suggests the absence of a selection bias; 2) selfreported data may be skewed due to inconsistent personal feelings or memories. However, the AUDIT questionnaire has been internationally validated in adolescents and young adults; 3) the most appropriate definition of HED in Spain implies differences between sexes: more than

290 five alcoholic beverages for women and more than six for men, on a single occasion. The third question of the AUDIT therefore underestimates the prevalence of HED in women.

292 However, this limitation will mainly affect descriptive and not analytical statistics; 4) subjects 293 may have minimized the role of alcohol in the occurrence of injuries; 5) subjects were not 294 asked how many injuries they had suffered, only whether they had or had not suffered an 295 injury; 6) when subjects responded "Yes, but not in the last year" we only considered that this 296 was a new instance of injury if the subject had not reported a previous alcohol-related injury 297 in a previous AUDIT.

\section{Conclusions}

299 We can conclude that heavy episodic drinking leads to an increase of alcohol-related injuries 300 among both male and female college students. This shows a new dimension on the 301 consequences of this public concern already related with a variety of health and social 
Heavy Episodic Drinking \& Alcohol-Related Injuries

302 problems. Furthermore, our results allow us to suggest that about one third of alcohol-related

303 injuries could be avoided by removing this consumption pattern.

304 
Heavy Episodic Drinking \& Alcohol-Related Injuries

305 Acknowledgements

306 Funding: This work was supported by the Spanish National Plan on Drugs (N.P.D)(grant

307 number 2005/PN014), and MICINN (grant number PSI2011-22575).

308 The authors declare that there are no conflicts of interest.

309 
Heavy Episodic Drinking \& Alcohol-Related Injuries

\section{REFERENCES}

Ahlström, S., 2011. Consumo nocivo de alcohol entre estudiantes europeos: resultados del ESPAD. Manole Ltda. Brasil. 90-101. Available at: http://www.cisa.org.br/UserFiles/File/alcoolesuasconsequencias-es-cap4.pdf

Álvarez-Bueno, C., Rodríguez-Martín, B., García-Ortiz, L., Gómez-Marcos, M.A., MartínezVizcaíno, V., 2015. Effectiveness of brief interventions in primary health care settings to decrease alcohol consumption by adult non-dependent drinkers: a systematic review of systematic reviews. Prev Med. 76, 33-8. doi: 10.1016/j.ypmed.2014. 12.010.

Anderson, BM., Stevens, M.C., Meda, S.A., Jordan, K., Calhoun, V, D., Pearlson, G.D., 2011. Functional imagin of cognitive control during acute alcohol intoxication. Alcohol Clin Exp Res. 35, 156-65. doi: 10.1111/j.1530-0277.2010.01332.x.

Andersson, C., Johnsson, K.O., Berglund, M., Ojehagen, A., 2007. Alcohol involvement in Swedish University freshmen related to gender, age, serious relationship and family history of alcohol problems. Alcohol Alcohol. 42(5), 448-55. doi: 10.1093/alcalc/agm008.

Bates, M.E., Labouvie, E.W., 1997. Adolescent risk factors and the prediction of persistent alcohol and drug use into adulthood. Alcohol Clin Exp Res. 21(5), 944-50. doi: 10.1111/j.1530-0277.1997.tb03863.x.

Bewick, B.M., Mulhern, B., Barkham, M., Trusler, K., Hill, A.J., Stiles, W.B., 2008. Changes in undergraduate student alcohol consumption as they progress through university. BMC Public Health. 8, 163. doi: 10.1186/1471-2458-8-163.

Borges, G., Cherpitel, C.J., Rosovsky, H., 1998. Male drinking and violence-related injury in the emergency room. Addiction. 93(1), 103-12. doi: 10.1046/j.13600443.1998.93110310.x. 
Heavy Episodic Drinking \& Alcohol-Related Injuries

Caamaño-Isorna, F., Moure-Rodriguez, L., Corral Varela, M., Cadaveira, F., 2017. Traffic accidents and heavy episodic drinking among university students. Traffic Inj Prev. $18(1), 1-2$

Calafat, A., 2002. Estrategias preventivas del abuso de alcohol. Adicciones. 14(suppl 1), 31735. doi: 10.20882/adicciones.531.

Cooper, M.L., 2002. Alcohol use and risky sexual behavior among college students and youth: evaluating the evidence. J Stud Alcohol. (suppl 14), 101-17. doi: $10.15288 /$ jsas.2002.s14.101.

Cortés, M.T., Espejo, B., Giménez, J.A., Luque, L., Gómez, R., 2011. Beliefs associated with intensive alcohol consumption among adolescents [in Spanish]. Health and Addictions / Salud y Drogas. 11(2), 179-202.

Delegación del Gobierno para el Plan Nacional sobre Drogas., 2013. Encuesta sobre uso de drogas en Enseñanzas Secundarias en España (ESTUDES), 1994-2012. Madrid: Ministerio de Sanidad, Servicios Sociales e Igualdad.

Graham, K., Bernards, S., Knibbe, R., Kairouz, S., Kuntsche, S., Wilsnack, S.C., Greenfield, T.K., Dietze, P., Obot, I., Gmel, G., 2011. Alcohol-related negative consequences among drinkers around the world. Addiction. 106(8), 1391-405. doi: 10.1111/j.13600443.2011.03425.x.

Grant, J.D., Scherrer, J.F., Lynskey, M.T., Lyons, M.J., Eisen, S.A., Tsuang, M.T., True, W.R., Bucholz, K.K., 2006. Adolescent alcohol use is a risk factor for adult alcohol and drug dependence: evidence from a twin design. Psychol Med. 36(1), 109-18.

Griffith, E., 1997. Alcohol policy and the public good. Addiction. 92(suppl 1), 73-9.doi: 10.1111/j.1360-0443.1997.tb03399.x.

Guerri, C., Pascual, M., 2010. Mechanisms involved in the neurotoxic, cognitive, and neurobehavioral effects of alcohol consumption during adolescence. Alcohol. 44, 15- 
Heavy Episodic Drinking \& Alcohol-Related Injuries

26. doi: 10.1016/j.alcohol.2009.10.003.

Ivano Scandurra, R., García-Altés, A., Nebot, M., 2011. Social impact of abusive alcohol consumption in Spain: consumption, cost and policies [in Spanish]. Rev. Esp Salud Publica. 85(2), 141-7. doi: 10.1590/S1135-57272011000200003.

Jernigan, D.H., 2001. Global Status Report: Alcohol and Young People. Geneva: Substance Abuse Department of Social Change and Mental Health, World Health Organization. Available at: http://apps.who.int/iris/bitstream/10665/66795/1/WHO_MSD_MSB_01.1.pdf

Kandeld, D.B., Logan, JA., 1984. Patterns of drug use from adolescence to young adulthood: I. periods of risk for initiation, continued use, and discontinuation. Am J. Publ Health. 74(7), 660-6. doi: 10.2105/AJPH.74.7.660.

Kypri, K., Paschall, M.J., Langley, J., Baxter, J., Cashell-Smith M., Bourdeau, B., 2009. Drinking and alcohol-related harm among New Zealand university students: findings from a national Web-based survey. Alcohol Clin Exp Res. 33(2), 307-14. doi: 10.1111/j.1530-0277.2008.00834.x.

Laixuthai, A., Chaloupka, F.J., 1993. Youth alcohol use and public policy. Contemp Policy Issues. 11(4), 70-81. doi: 10.1111/j.1465-7287.1993.tb00402.x.

Larimer, M.E., Cronce, J.M., 2007. Identification, prevention, and treatment revisited: individual-focused college drinking prevention strategies 1999-2006. Addict Behav. 32(11), 2439-68. doi: 10.1016/j.addbeh.2007.05.006.

Llorca, J., Fariñas-Álvarez, C., Delgado-Rodríguez, M., 2001. Population attributable fraction: estimation and interpretation [in Spanish]. Gac Sanit. 15(1), 61-7. doi: 10.1016/S0213-9111(01)71519-1.

Mcleod, R., Stockwell, T., Stevens, M., Phillips, M., 1999. The relationship between alcohol consumption patterns and injury. Addiction. 94(11), 1719-34. doi: 10.1046/j.1360- 
Heavy Episodic Drinking \& Alcohol-Related Injuries

0443.1999.941117199.x.

Mota, N., Álvarez-Gil, R., Corral, M., Rodríguez Holguín, S., Parada, M., Crego, A., CaamañoIsorna, F., Cadaveira, F., 2010. Risky alcohol use and heavy episodic drinking among Spanish university students: A two-year follow-up. Gac Sanit. 24(5), 372-7. doi: 10.1016/j.gaceta.2010.02.013.

Moure-Rodríguez, L., Caamaño-Isorna, F., Doallo, S., Juan-Salvadores, P., Corral, M., Rodríguez-Holguín, S., Cadaveira, F., 2014. Heavy drinking and alcohol-related injuries in college students. Gac Sanit. 28(5), 376-80. doi: 10.1016/j.gaceta.2014.02.017.

Moure-Rodríguez, L., Doallo, S., Juan-Salvadores, P., Corral, M., Caamaño-Isorna, F., 2016. Heavy episodic drinking, cannabis use and unsafe sex among university students. Gac Sanit. doi: 10.1016/j.gaceta.2016.03.007.

Moure-Rodríguez, L., Piñeiro, M., Corral Varela, M., Rodríguez-Holguín, S., Cadaveira, F., Caamaño-Isorna, F., 2016. Identifying Predictors and Prevalence of Alcohol Consumption among University Students: Nine Years of Follow-Up. PLoS One. 11(11), e0165514. doi: 10.1371/journal.pone.0165514.

Mundt M.P., Zakletskaia L.I., Fleming M.F. Extreme college drinking and alcohol related injury risk. Alcohol Clin Exp Res. 2009;33:1532-8.

National Institute on Alcohol Abuse and Alcoholism. Drinking Levels Defined. http://www.niaaa.nih.gov/alcohol-health/overview-alcohol-consumption/moderatebinge-drinking. (April 2016, date last accessed).

Obot, I.S., Room, R., 2005. Alcohol, gender and drinking problems: perspectives from low and middle income countries. Geneva: Department of Mental Health and Substance Abuse, World Health Organization. 
Heavy Episodic Drinking \& Alcohol-Related Injuries on Alcohol Abuse and Alcoholism. Available from: http://pubs.niaaa.nih.gov/publications/arh284/202-204.htm

Pickett, W., Schmid, H., Boyce, W.F., Simpson, K., Scheidt, P.C., Mazur, J., Molcho, M., King, M.A., Godeau, E., Overpeck, M., Aszmann, A., Szabo, M., Harel, Y., 2002. Multiple risk behavior and injury: an international analysis of young people. Arch Pediatr Adolesc Med. 156(8), 786-93. doi:10.1001/archpedi.156.8.786.

Powell, LM., Williams, J., Wechsler, H., 2004. Study habits and the level of alcohol use among college students. Education Economics. 12(2), 135-49. doi: 10.1080/0964529042000239159.

Rehm, J., Gmel, G., Sempos, C.T., Trevisan, M., 2002. Alcohol-Related Morbidity and Mortality. Alcohol Res Health. 27(1), 39-51.

Reich, R.R., Cummings, J.R., Greenbaum, P.E., Moltisanti, A.J., Goldman, M.S., 2015. The temporal "pulse" of drinking: Tracking 5 years of binge drinking in emerging Adults. J Abnorm Psychol. 124(3), 635-47. doi: 10.1037/abn0000061.

Sassi, F., 2015. Tackling Harmful Alcohol Use: Economics and Public Health Policy. Paris: OECD. doi: http://dx.doi.0rg/10.1787/9789264181069

Saunders,J.B., Aasland, O.G., Babor, T.F., De la Fuente, J.R., Grant, M., 1993. Development of the Alcohol Use Disorders Identification Test (AUDIT): WHO collaborative project on early detection of persons with harmful alcohol consumption-II. Addiction. 88(6), 791-804. doi: 10.1111/j.1360-0443.1993.tb02093.x.

Schulenberg, J., O'Malley, P.M., Bachman, J.G., Wadsworth, K.N., Johnston, L.D., 1996. Getting drunk and growing up: trajectories of frequent binge drinking during the transition to young adulthood. J Stud Alcohol. 57(3), 289-304. doi: 10.15288/jsa.1996.57.289.

434 Valencia-Martín JL, Galán I, Rodríguez-artalejo F, Lorenzo J, Valencia-Martin JL, Galan I, et 
Heavy Episodic Drinking \& Alcohol-Related Injuries al. The joint association of average volume of alcohol and binge drinking with hazardous driving behaviour and traffic crashes. Addiction. 2008;103(5):749-57

Varela, J., Braña, T., Real, E., Rial, A., 2005. Validación empírica do AUDIT (Cuestionario de Identificación dos trastornos debidos ó consumo de alcohol) na poboación xeral galega (Validation of AUDIT for Galician population). Consellería de Sanidad-Sergas (Xunta de Galicia). Santiago de Compostela, Spain.

Watt, K., Purdie, D.M., Roche, A.M., McClure, R.J., 2004. Risk of injury from acute alcohol consumption and the influence of confounders. Addiction. 99(10), 1262-73. doi: 10.1111/j.1360-0443.2004.00823.x.

Wechsler, H., Lee, J.E., Nelson, T.F., Lee, H., 2003. Drinking and driving among college students: The influence of alcohol-control policies. Am J Prev Med. 25(3), 212-8. doi: 10.1016/S0749-3797(03)00199-5.

Wicki, M., Kuntsche, E., Gmel, G., 2010. Drinking at European universities? A review of students' alcohol use. Addict Behav. 35(11), 913-24. doi: 10.1016/j.addbeh.2010.06.015.

Wiersma, J.D., Fischer, J.L., 2014. Young adult drinking partnerships: alcoholrelated consequences and relationship problems six years later. J Stud Alcohol Drugs. 75(4), 704-12. 


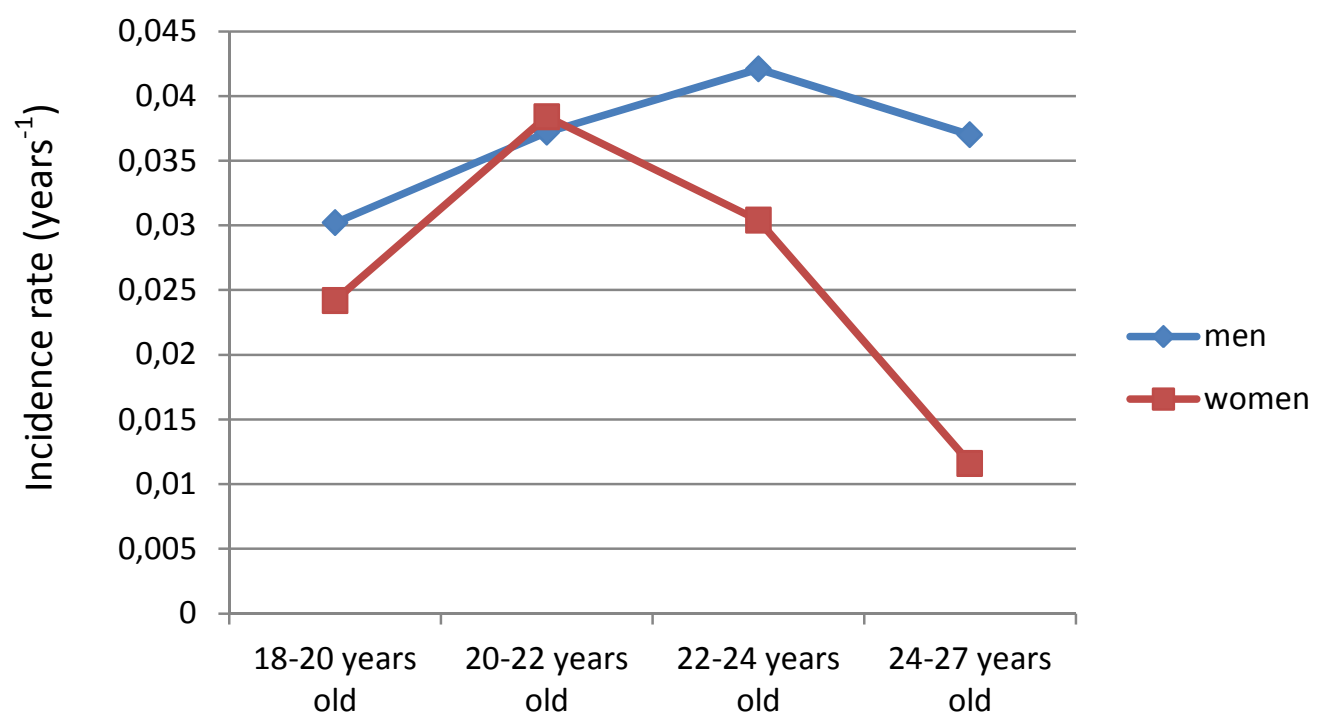

